\title{
Structural Analysis of the Mediating Role of Organizational Commitment in the Relationship between Organizational Agility and Organizational Intelligence with Organizational Performance (Case Study: Northwest University Jihad Units)
}

\author{
Shiva Habibzade*, Alireza Ghaleei, Behnaz Mohajeran, Mohamad Hasani \\ Urmia University, Urmia, Iran \\ * Corresponding author's Email: habibzade@acecr.ac.ir
}

\begin{abstract}
The purpose of this study is structural analysis of the mediating role of organizational commitment in the relationship between organizational agility and organizational intelligence with organizational performance among academic center of education units in the northwest of Iran. The study method is descriptive-correlational and the statistical population including all employees of the Northwestern academic center of education units (West Azerbaijan and East Azerbaijan, Ardabil and Kurdistan), which consist of total of 320 people. The sample size is 206 people who are selected by stratified random sampling method according to the size of the population. Standard questionnaires of organizational performance, organizational agility, organizational intelligence and organizational commitment are used to collect data. The content validity of the instruments is confirmed by experts and an appropriate validity level is reported for them. Confirmatory factor analysis is also used for the construct validity of the instruments. Reliability coefficients for organizational commitment, organizational intelligence, organizational agility and organizational performance questionnaires were reported to be.79,.89,.87, and .4 , respectively. To analyze the data, descriptive statistics techniques including bar graphs, mean and standard deviation and inferential statistics including multiple regression and structural equation modeling are used. The results revealed that organizational intelligence, organizational agility and organizational commitment have a direct impact on organizational performance. Also, organizational intelligence and organizational agility had an indirect effect on organizational performance by mediating role of organizational commitment. Therefore, it is suggested that the managers of academic center of education units pay more attention to establishing and implementing organizational intelligence and organizational agility to increase organizational commitment and ultimately improve organizational performance.
\end{abstract}

Keywords: Organizational Performance, organizational agility, organizational intelligence, organizational commitment, Academic Jihad

\section{Introduction}

Current organizations must have competitive capabilities in order to deal appropriately with changing market conditions and deal with competitors. In this way, they will provide the ground for survival in a turbulent environment and will also have a better performance and maintain themselves in the market (Ebrahimpour, Yaghubi, \& Zahedi, 2016). Organizational performance is a reflection of an organization method in using tangible and intangible resources to achieve organizational goals and a wide range of intangible receipts, such as increasing organizational knowledge (Ek \& Mukuru, 2013). It should also be noted that performance improvement is one of the most important goals of an organization and every organization tries to strengthen these outputs in various ways (Iqbal, Latif, Marimon, Sahibzada, \& Hussain, 2019). To achieve this goal, relevant factors affecting organizational performance must be identified and strengthened (Urban \& Joubert, 2017).

In today's world where change has become the determining factor and the main ability of organizations to survive, high performance depends on the ability to understand change and plans to create a suitable environment for innovation from these changes (Ardashir Bazrkar \& Hajiohammadi, 2019). One of 
these methods that has been considered by researchers in the last decade is the discussion of organizational agility (Saeed, Sami, Lodhi, \& Iqbal, 2013). In fact, an agile organization is an organization that has characteristics such as innovation, flexibility and readiness to react to environmental changes, and it is very resilient when facing with problems and shortcomings (Rzepka \& Bojar, 2020). Agile organization always seeks to use potential opportunities and create stable conditions for its capabilities and innovations (Haidari, Siadat, Hovaida, \& Shahin, 2014).

Organizational agility actually requires a fundamental ability to sense, perceive, analyze, and anticipate changes in the organizational environment (Ghafuri, Farhadi, \& Mansouri, 2014). Agility is a broad business capability that includes organizational structures, information systems, support processes and especially a set of ideas (Shiri, Mohsenimoghadam, \& Faizi, 2014). Therefore, academic center for education and culture as an educational-research organization should be organized in a direction that has the ability to deal with environmental changes (Mosleh \& Allahyari Bouzanjan, 2014). Therefore, its human and physical resources are organized in a way that can quickly adapt to the changing environment and opportunities in the market (EbrahimiyanJelodar \& EbrahimiyanJelodar, 2012). Therefore, academic center for education and culture, as an influential organization on the academic community, should be given 4 percent, with 10, 7, 10, and 6 percent, and at 3 o'clock in the hands of colleagues (Gopalakrishnan, Libby, Samuels, \& Swenson, 2015). Organizational intelligence enables us to make decisions about all factors affecting the organization and companies (Howson, 2007). The promise that organizational intelligence gives to a manager is the promise of immediate access to all data in the organization with digital dashboards and performance indicators (Mahmoudi, Yousefi, Khazaei, \& Eskandari, 2019).

Loyal and compatible human resources with organizational goals and values are willing to work beyond the prescribed duties; it can be an important factor in organizational effectiveness (Mahmoudi et al., 2019). Organizational commitment is often present when a person maintains his/her extra-role behaviors despite job satisfaction reduction at the lowest level of expectation (Berberoglu, 2018). Employee commitment to the organization is a deep and broad feature that includes almost all known aspects of human resource management (Yousef, 2017). If managers do not pay proper attention to the personality traits of human resources, in response to this managerial weakness, employees will not feel committed to their job (Farrukh, Ying, \& Mansori, 2017).

Finally, it should be noted that in today's complex and competitive world, if organizations do not think about establishing competitive paradigms such as intelligence and agility, they will certainly not be able to meet the needs of their employees. The reduction of the retention and organizational commitment of employees will lead to the reduction of organizational function speed (Farhadinejad, Eynali, \& Bagheri Garbollagh, 2020) and its certain failure.

The results of Bani Na'm and Amirnejad (2016) show that the components of strategic flexibility have a positive and significant effect on organizational agility and also organizational agility has a positive and significant effect on organizational commitment. Findings show the mediating effect of organizational commitment on the relationship between strategic flexibility and organizational agility. Aminbeidokhti, Mohammadi Hoseini, and Hosseinpoor (2016) conclude that entrepreneurship has a direct effect on organizational agility, and organizational commitment plays a mediating role in the relationship between entrepreneurship and organizational agility. Jourkesh, Shokrchizadeh, and Sarjoui $\underline{(2015)}$ indicate that organizational agility and its components (responsiveness, competence, flexibility and speed) have a significant effect on teachers' performance.

Panda and Rath (2018) conclude that intelligent organizational infrastructure, namely work functions, interpersonal management, and technology management skills, demonstrate organizational agility. 
Berberoglu (2018) have found that organizational commitment is most relevant to performance when external pressures to force a person to stay in that job are minimal. In their research, Cegarra-Navarro, Soto-Acosta, and Wensley (2016) conclude that there is a positive and significant relationship between knowledge management processes and organizational agility. The results of Harraf, Wanasika, Tate, and Talbott (2015) study show that organizational agility has a direct and significant effect on organizational performance, and agile organizations generally have individual and organizational performance and a high level of innovation. Sanadgol (2014) conclude that there is a significant positive relationship between organizational agility and managers' job satisfaction; employee's satisfaction is effectively affected by their agility. The results of Sherehiy and Karwowski (2014) show a significant relationship between organizational performance and organizational agility. Findings of Nafei (2016) show that the dimensions of organizational agility can improve organizational performance.

Therefore, according to the above information and the importance of the two paradigms of organizational intelligence and agility in achieving their goals, it is necessary to pay attention to the fact that the effects of these two basic paradigms with respect to the mediating role of organizational commitment on unit performance of academic center for education and culture in the northwest of the country should be examined. Therefore, in the present study, in order to predict the possible relationships between the research variables, to examine the direct and indirect effects of the mentioned variables and to estimate the fit coefficient, the following conceptual model is designed and tested.

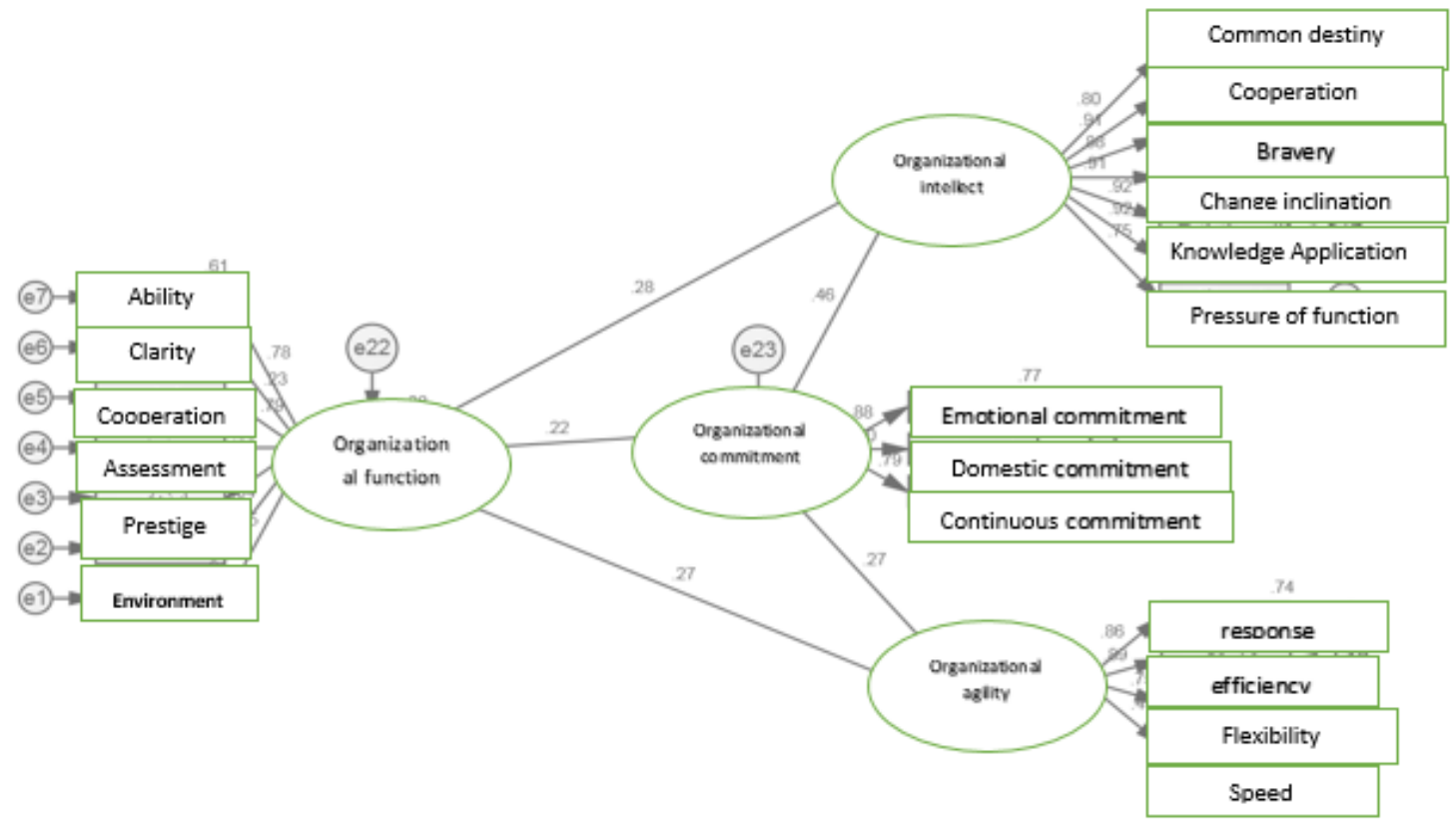

Figure 1. Conceptual model of research (inferred by the researcher according to studies) 


\section{Material and Methods}

The present study is a correlational study using structural equation modeling. Both simple correlation (correlation matrix) and causal model of structural equations have been used to determine the possible relationships and their effects on each other. The statistical population of the present study includes all employees of the Northwestern University of academic center units, including west and east of Azerbaijan, Ardabil and Kurdistan, and about 320 people. The sample size was calculated based on Morgan table 175 people. Because the purpose of the research is structural modeling by structural equation method and it is necessary to use this method, the sample size is at least 200 people.

Cochran's formula has been used to determine the sample size according to the size of the statistical population. The following table shows the statistical sample size, proportional to the volume of each unit.

Table 1. Class sampling of academic center units

\begin{tabular}{|c|c|c|}
\hline Unite name & Number of employees & Number of samples selected from employees \\
\hline West Azarbayejan & 80 & 55 \\
\hline East Azarbayejan & 85 & 57 \\
\hline Ardabil & 75 & 48 \\
\hline Kordestan & 80 & 55 \\
\hline Total & 320 & 215 \\
\hline
\end{tabular}

The main data collection tools are four questionnaires as follows:

A) Organizational Commitment Questionnaire: Allen and Meyer (1996) organizational commitment questionnaire has been used. This questionnaire measures organizational commitment in the form of 24 items and 3 components (emotional commitment 1 to 8, continuous commitment 9 to 16 and normative commitment 17 to 24) and on a 7-point scale that includes "I strongly agree" options (7), "Relatively agree", "slightly agree", "have no opinion", "slightly disagree", "relatively disagree" and "strongly disagree" (1). Subjects must answer one of the 7 options for each question and then score based on values of $1,2,3,4,5,6,7$. In this questionnaire, the maximum score is 168 points and the minimum is 24. It should be noted that questions 4, 5, 6, 8, 9, 10, 15, 16, 17, 18, 19, 21 and 24 have a reverse scoring method. Score between 24 and 64: Organizational commitment is weak. Score between 64 and 96: Medium organizational commitment. Score above 96: Strong organizational commitment. This questionnaire has three dimensions: emotional, continuous and normative.

B) Organizational Intelligence Questionnaire: Albrecht (2002) standardized organizational intelligence questionnaire is used to measure organizational intelligence. This organizational intelligence questionnaire is in the form of 46 items and 7 components that include common insights that evaluate questions (2-3-15-17-22-42-48), common destiny questions (4-9-19-33-36-44- 47), the desire to change questions (13-14-24-2834-43-45), courage (1-5-6-10-25-37-40), unity and agreement of questions (12-18-20 -26-38-39-41), the application of knowledge of questions (7-21-23-29-30-31-35) and the pressure of performance of questions (8-11-16-27-32-46-49). This questionnaire also consists of a 5-point spectrum that includes some options (completely disagree, disagree, somewhat agree, agree, completely agree).

C) Organizational Agility Questionnaire: To standardize organizational agility, the standardized organizational agility questionnaire of Sharifi and Zhang (1999) is used. This questionnaire measures 
organizational agility in the form of 16 items and 4 components (responsiveness, competence, flexibility and speed) on a 5-point Likert scale.

D) Organizational Performance Questionnaire: To measure organizational performance, the standardized organizational performance questionnaire of Hersey and Goldsmith is used. This questionnaire in the form of 42 items and seven components of ability (items 1-2-3-20), clarity (items 4-5-6-7-8-38-39), help (items 9-11-12) -13-15), incentives (items 16-18-19-21-22-25), evaluation (items 23-30-31-32-33-34-35-36-37), credibility (items 17-24 -26-27-28-29), and the environment (items 1014-40-41-42) and in the form of a 5-point Likert scale (very low, 1; low, 2; medium 3; high, 4; very high, 5;) is measured.

Cronbach's alpha is used to determine the reliability of the questionnaires, which is $.79, .89, .87, .84$ for organizational commitment, organizational intelligence, organizational agility and organizational performance questionnaires, respectively. Also, the face validity of all questionnaires is confirmed by experts and professors in the field of management and behavioral sciences. Finally, confirmatory factor analysis is used to assess the construct validity of the questionnaires, the results of which are described in the table below.

Table 2. Construct validity of the questionnaires

\begin{tabular}{|c|c|c|c|c|}
\hline Index & Organizational commitment & Organizational function & Organizational intelligence & Organizational agility \\
\hline CMIN & 2.11 & 2.34 & 2.08 & 2.17 \\
\hline RMSEA & .05 & .07 & .07 & .06 \\
\hline GFI & .98 & .95 & .97 & .99 \\
\hline AGFI & .96 & .91 & .93 & .97 \\
\hline CFI & .99 & .96 & .98 & .99 \\
\hline NFI & .98 & .95 & .95 & .99 \\
\hline SMR & .02 & .04 & .03 & .04 \\
\hline
\end{tabular}

\section{Results}

Before examining the theoretical model of the research, there should be a significant correlation between the variables of the theoretical model. Therefore, in Table 3, correlation matrices of research variables are reported to examine their relationship.

Table 3. Correlation matrix of research variables

\begin{tabular}{|c|c|c|c|}
\hline Variables & 1 & 2 & 3 \\
\hline 1.Organization intelligence & 1 & & \\
\hline 2.Organization agility & $.44 * *$ & 1 & \\
\hline 3.Organization commitment & $.54 * *$ & $.30 * *$ & 1 \\
\hline 4.Organization performance & $.53 * *$ & $.44 * *$ & $.52 * *$ \\
\hline
\end{tabular}
$* * \mathrm{p}<.01$

According to the above table, the relationship between organizational intelligence (.53), organizational agility (.44) and organizational commitment (.52) with organizational performance is positive and significant at the level of .01. The relationship between organizational intelligence (.54) and organizational agility (.30) with organizational commitment is also positive and significant at the level of .01. 
Testing the theoretical model of research: Figure 2 shows the tested research model. AMOS 22 software is used to test this model. Also, in Table 4, the results related to direct effect coefficients are reported.

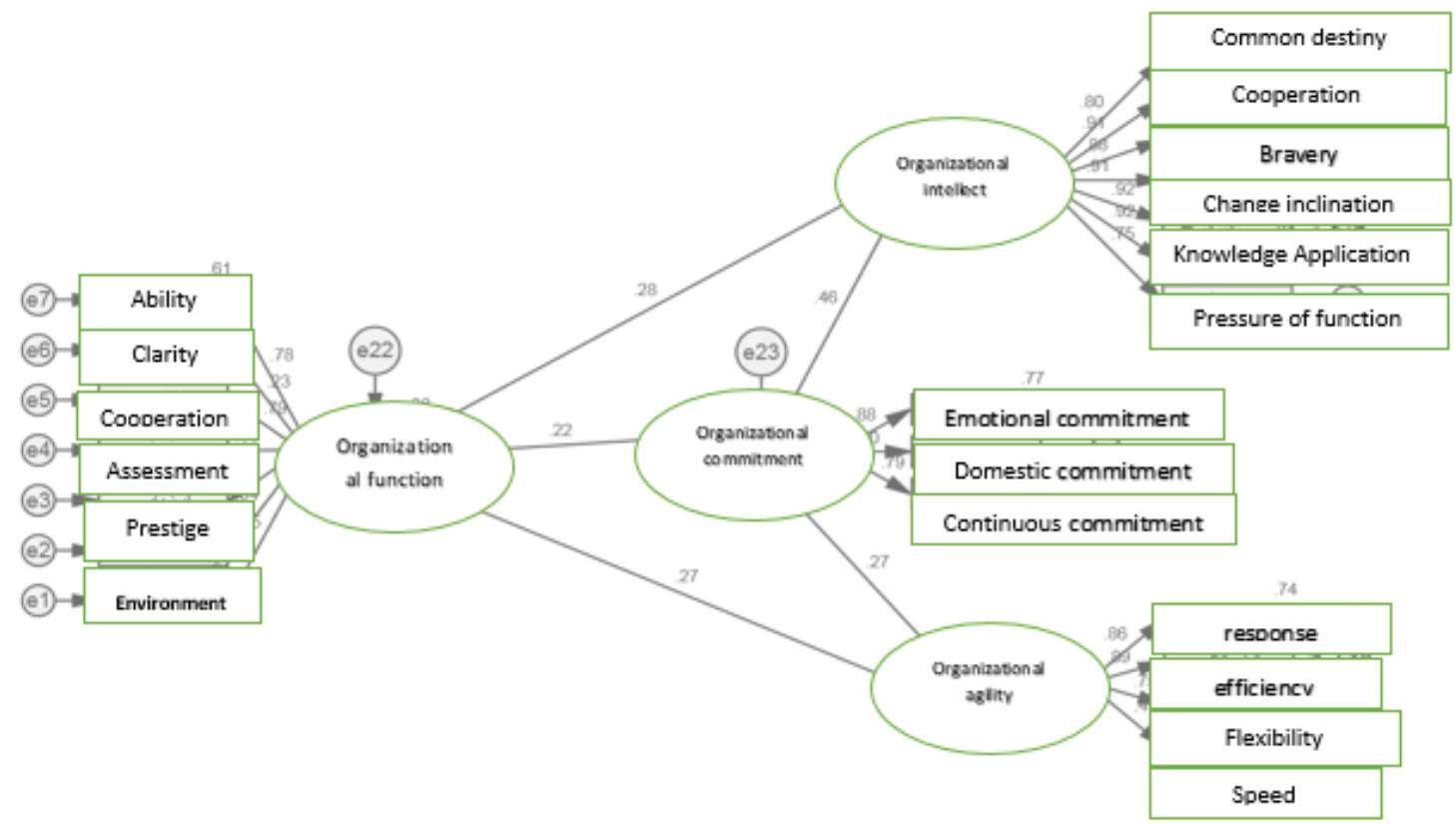

Figure 2. Tested model of research

Tale 4. Goodness of fit in tested research model

\begin{tabular}{|c|c|c|c|}
\hline \multicolumn{4}{|l|}{ Index of absolute fit } \\
\hline Index & GFI & AGFI & SRMR \\
\hline The value obtained & .96 & .93 & .03 \\
\hline Acceptable limit & More than .90 & More than .80 & less than .05 \\
\hline \multicolumn{4}{|c|}{ Index of compatible fit } \\
\hline Index & $\mathrm{CFI}$ & NFI & NNFI \\
\hline Value obtained & .95 & .92 & .95 \\
\hline Acceptable limit & More than .90 & More than .90 & More than .90 \\
\hline \multicolumn{4}{|l|}{ Index of balanced fit } \\
\hline Index & $\mathrm{X}^{2} / \mathrm{df}$ & PNFI & RMSEA \\
\hline Value obtained & 2.53 & .62 & .06 \\
\hline Acceptable limit & Less than 3 & More than .60 & Less than .08 \\
\hline
\end{tabular}

According to Table 4 for the tested model, the goodness of fit index (GFI) is (.96) which is more than (.90). The adjusted fitness index (AGFI) is (.93) which is higher than (.80). And the root mean square residual (RMSR) is (.03) which is less than (.05). The adaptive fit index (CFI) is (.95) which is higher than (.90). The normalized fit index (NFI) is (.92) which is higher than (.90). The non-normalized fit index (NNFI) is (.95) which is higher than (.90). The square of the degree of freedom $\left(\mathrm{X}^{2} / \mathrm{df}\right)$ is 2.53 which is less than 3. The Parsimonious Normed Fit Index (PNFI) (.62) which is more than (.60) and the 
root mean square error (RMSEA) is (.06) which is less than (.08). According to these findings, it can be said that the tested model of the research has a good fit.

Investigation of research hypotheses: Main research hypothesis: Organizational commitment has a mediating role in the relationship between organizational agility and organizational intelligence with organizational performance. Tables 5 and 6 report the results of structural equation modeling for this hypothesis.

Table 5. Direct effects of the tested research model

\begin{tabular}{|l|c|c|c|}
\hline Path & Direct effect & T statistics & $\boldsymbol{p}$ \\
\hline Organizational commitment & .22 & 2.67 & .001 \\
\hline Organizational intelligence & .28 & 3.65 & .001 \\
\hline Organizational agility & .27 & 3.68 & .001 \\
\hline
\end{tabular}

Table 6. Indirect effects of organizational intelligence and organizational agility on organizational performance (mediated by organizational commitment)

\begin{tabular}{|l|c|c|c|}
\hline Path & Indirect effect & T statistics & $\boldsymbol{p}$ \\
\hline organizational intelligence & .46 & 6.25 & .001 \\
\hline organizational agility & .27 & 3.73 & .001 \\
\hline
\end{tabular}

According to Table 5, the direct effect of organizational commitment on organizational performance (.22) is positive and significant at the level of .01. The direct effect of organizational intelligence on organizational performance (.28) is positive and significant at the level of .001. The direct effect of organizational agility on organizational performance (.27) is positive and significant at the level of .001. Also in Table 6, the indirect effect of organizational intelligence on organizational commitment (0.46) is positive and significant at the level of 0.001 . The indirect effect of organizational agility on organizational commitment (.27) is positive and significant at the level of .001.

Sub-hypothesis 1: Organizational intelligence has a direct causal relationship with organizational performance.

Sub-hypothesis 2: Organizational agility has a direct causal relationship with organizational performance.

Sub-hypothesis 3: Organizational commitment has a direct causal relationship with organizational performance.

Table 7. Structural equation modeling results related to the 1-3 sub-hypotheses

\begin{tabular}{|c|c|c|c|c|c|}
\hline $\begin{array}{l}\text { Sub- } \\
\text { hypothesis }\end{array}$ & Non-standardized parameter & Path coefficient & Standard estimation error & $\begin{array}{l}\text { T } \\
\text { value }\end{array}$ & $\boldsymbol{p}$ \\
\hline 1 & .26 & .28 & .07 & 3.65 & .001 \\
\hline 2 & .56 & .27 & .15 & 3.68 & .001 \\
\hline 3 & .47 & .22 & .12 & 2.68 & .001 \\
\hline
\end{tabular}

According to Table 7, in the case of organizational intelligence, non-standardized parameters have a direct effect on organizational performance (.26). The standardized direct effect for this path is (.28). 
The t-statistic of this effect is 3.65, which is positive and significant at the level of .001. Also, the nonstandardized parameter is the direct effect of organizational agility on organizational performance (.56). The standardized direct effect for this path is (.27). The t-statistic of this effect is 3.68 , which is positive and significant at the level of .001. According to Table 7, non-standardized parameters have a direct effect of organizational commitment on organizational performance (.47). The direct effect is standardized for this path (.22). The t-statistic of this work is (2.68) which is positive and significant at the level of .001 .

Sub-hypothesis 4: Organizational intelligence has an indirect causal relationship with organizational performance through organizational commitment.

Sub-hypothesis 5: Organizational agility has an indirect causal relationship with organizational performance through organizational commitment.

Table 8. Structural equation modeling results related to the fourth sub-hypothesis

\begin{tabular}{|l|l|l|l|l|l|l|}
\hline Sub-hypothesis & $\begin{array}{l}\text { Non-standardized } \\
\text { parameter }\end{array}$ & Path coefficient & $\begin{array}{l}\text { Standard } \\
\text { estimation error }\end{array}$ & $\boldsymbol{p}$ & $\begin{array}{l}\text { Low } \\
\text { limit }\end{array}$ & $\begin{array}{l}\text { High } \\
\text { limit }\end{array}$ \\
\hline 4 & .09 & .10 & .05 & .05 & .02 & .19 \\
\hline 5 & .12 & .06 & .04 & .05 & .01 & .14 \\
\hline
\end{tabular}

According to Table 8, the non-standardized parameter is the indirect effect of organizational intelligence through organizational commitment on organizational performance (.09). The standardized indirect effect for this path is (.10) which is positive and significant at the level of .05. Furthermore, the nonstandardized parameter is the indirect effect of organizational agility through organizational commitment on organizational performance (.12). The standardized indirect effect for this path is (.06) which is positive and significant at the level of .05.

\section{Discussion}

The purpose of this study is to model the structural role of mediating organizational commitment in the relationship between organizational agility and organizational intelligence with organizational performance among the units of Northwestern Academic Centers. In order to achieve the above goal, hypotheses are designed and tested, including the facts that organizational commitment has a mediating role in the relationship between organizational agility and organizational intelligence with organizational performance. In explaining these results, it can be said that the prerequisite for an organization with good performance is that the responsibilities of individuals in the organization be clear. The service compensation system and the path of career advancement in the organization should be such that employees feel that they are evaluated based on performance and provide the conditions for the growth and development of the organization. Also, paying attention to the quality of work life of employees and creating an environment in which employees feel proud and mature to work and redouble their efforts to achieve the goals of the organization, will increase employee's commitment and their performance. In this regard, attention to the role of organizational intelligence and agility should be the 
basis of organizational programs and strategies. In order to explain the results of the above hypothesis, the following research hypotheses are discussed separately.

The results also show that organizational intelligence has a positive effect on the performance of managers in Academic Center Organization in the northwest of Iran. In explaining these results, it can be said that organizational intelligence helps people to realize the weaknesses of their organization and strengthen their strengths. They also provide an appropriate platform for creating knowledge management and organizational learning and promote the power of ideation, creativity and innovation, which improves the performance of individuals and also emphasizes the clear expression of strategic goals and missions. Focusing on teamwork and efforts, focusing on solving challenges in the organization, paying attention to the need for change, supporting employee performance and human and emotional communication between managers and employees has led to a correlation between organizational intelligence and organizational performance. This finding is in line with the results of earlier studies (Ardeshir Bazrkar \& Hajimohammadi, 2021; Mahmoudi et al., 2019; Rezaei Kalantari \& Nouri, 2020), which have found that there is a significant relationship between managers' organizational intelligence and their performance.

The results show a positive and significant effect of organizational agility on organizational performance. In this regard, it can be stated that agility enhances organization's ability to offer high quality products and services and as a result becomes an important factor for organizational productivity. On the other hand, a high-performance organization is an organization that in a long period of time, adapts to changes, reacts quickly to these changes and creates a coherent and purposeful management structure, continuous improvement of key capabilities and appropriate treatment of employees. The results of this hypothesis are in line with the findings of previous studies (Harraf et al., 2015; Jourkesh et al., 2015; Nafei, 2016) as well.

In addition to the above results, the findings also indicate the impact of organizational commitment on organizational performance. Explaining this finding, it should be noted that if employees have an emotional connection with their organization and a strong sense of belonging, they will work in the organization with more motivation and interest, so such employees perform much better than employees who are not affiliated with their organization. They will be forced to enter the organization. Therefore, if employees believe in loyalty, continuing to work and doing work in the organization and consider these as their duty, they will be more inclined to perform higher and better. The results of the above hypothesis are confirmed by the findings of some studies (Ali, Rehman, Ali, Yousaf, \& Zia, 2010; Steyrer, Schiffinger, \& Lang, 2008) because they also achieved similar results in their research.

The results further show that organizational intelligence affects organizational performance through organizational commitment. In fact, it can be said that human capital is the most vital strategic element and the most basic strategy to increase the effectiveness and efficiency of the organization which leads to the progress and development of society. In dynamic environments, organizations face a series of unforeseen situations which are very difficult for one person to control. But an organization can face difficult situations, and these interactive patterns are called the set of intellects of the organization. The results of the present study are in line with the results of the research of Panda and Rath (2018) and Cegarra-Navarro et al. (2016).

Finally, the results show that organizational agility has a positive and significant effect on organizational performance through organizational commitment. In explaining these results, it can be said that the more 
agile the organization is, the higher the organizational commitment of employees; it will ultimately lead to the effectiveness and efficiency of the organization. Therefore, in order to increase the organizational commitment of the employees, while correctly explaining the goals and values of the organization, by establishing a useful and effective relationship with the employees, the goals and values of the employees should be known and efforts should be made to align these goals with the values of the organization. Therefore, it is necessary to provide the ground for employees to confidently use their experiences, abilities and capacities to promote organizational goals. This will not be possible unless the principles and rules of organizational commitment and organizational agility are identified and the necessary context is provided for the implementation of such behaviors. This finding is based on the results of previous studies (Aminbeidokhti et al., 2016; Cegarra-Navarro et al., 2016; Panda \& Rath, $\underline{2018}$.

The present study also has some limitations for researchers, such as the measurement tool which is a questionnaire. This tool has special limitations such as measuring the answers in the form of a multipoint Likert scale. Also, research data has been collected from the academic center of the northwestern units, so caution should be exercised in generalizing the results. Causal relationships between variables should also be used with caution, because structural equation modeling to express causal relationships between variables do not have strong explanations. Finally, according to the results of the research, the following suggestions are presented to the managers and administrators of the university jihad.

With considering the positive and significant effect of organizational intelligence on organizational performance, it is suggested that using professors and experts should be provided in the field of the concept and importance of organizational intelligence, in-service training classes for academic center, so they can improve their organizational intelligence rank and organizational performance in the organization.

Also, strengthening the performance of employee's evaluation system in the organization should be regularly inform the results of their performance so that they can identify their weaknesses and strengths in performing their assigned tasks and provide the basis for improving their performance. By considering the positive and significant effect of organizational agility on organizational performance, it is recommended that academic center officials establish a flexible organizational structure, eliminate cumbersome rules and regulations, develop staff careers, and prepare to face environmental changes in an integrated manner as well. They build information and processes to be able to increase organizational agility, which in turn provides the necessary conditions to improve organizational performance.

Finally, since the academic center units are the main players in the intelligent system, they are innovative, flexible and agile. It is suggested that they better turn to processes that, while dynamic, make them smarter and more agile in order to improve organizational performance.

Conflict of interest: The authors state no conflict of interest in the study.

Financial sponsor: The authors acknowledge that they have not received any financial support for all stages of the study, writing and publication of the paper. 
Acknowledgment: We hereby appreciate all the participants of the study as well as all those participating in the implementation of this project.

\section{References}

Albrecht, K. (2002). Organizational intelligence \& knowledge management: Thinking outside the silos. Executive White Paper, 1-17.

Ali, I., Rehman, K. U., Ali, S. I., Yousaf, J., \& Zia, M. (2010). Corporate social responsibility influences, employee commitment and organizational performance. African journal of Business management, 4(13), 2796-2801.

Allen, N. J., \& Meyer, J. P. (1996). Affective, continuance, and normative commitment to the organization: An examination of construct validity. Journal of Vocational Behavior, 49(3), 252-276.

Aminbeidokhti, A., Mohammadi Hoseini, S. A., \& Hosseinpoor, O. (2016). The Relationship between Organizational Entrepreneurship and Organizational Agility: Testing the Mediator Role of Organizational Commitment. Higher Education Letter, 9(35), 135-155.

Bani Na'm, J., \& Amirnejad, G. (2016). The effect of organizational agility on organizational performance with the mediating role of knowledge management in Bank Mellat branches of Khuzestan province studied in Ahvaz metropolis. Paper presented at the First National Conference on Management and World Economy, Tehran. civilica .com/doc/631457

Bazrkar, A., \& Hajimohammadi, M. (2021). The investigation of the mediating role of innovation and organizational intelligence on the relationship between knowledge management and financial performance of the organizations active in the e-banking industry. Independent Journal of Management \& Production, 12(1), 054-079.

Bazrkar, A., \& Hajiohammadi, M. (2019). Investigating the effect of knowledge management on the financial performance of the organization according to the mediating role of innovation and organizational intelligence. Journal of New Research Approaches in Management and Accounting, 3(26), 68-86.

Berberoglu, A. (2018). Impact of organizational climate on organizational commitment and perceived organizational performance: empirical evidence from public hospitals. BMC health services research, 18(1), 1-9.

Cegarra-Navarro, J.-G., Soto-Acosta, P., \& Wensley, A. K. (2016). Structured knowledge processes and firm performance: The role of organizational agility. Journal of Business Research, 69(5), 15441549.

EbrahimiyanJelodar, s. y., \& EbrahimiyanJelodar, s. m. (2012). Organization agility: Organization flexibility and responsion speed. POLICE HUMAN DEVELOPMENT, 8(39), 13-34.

Ebrahimpour, H., Yaghubi, N., \& Zahedi, S. S. (2016). Organizational Learning Capacity and Clinical Governance Implementation in Social Sequrity hospital (A Case Study). Hospital, 15(2), 75-83.

Ek, K., \& Mukuru, E. (2013). Effect of motivation on employee performance in public middle level Technical Training Institutions in Kenya. International Journal of Advances in Management and Economics, 2(4), 73-82.

Farhadinejad, M., Eynali, M., \& Bagheri Garbollagh, H. (2020). Reflection on Mum Effect: Analysis of the role of culture on the employee performance and organizational communication (Case of Study: 
governmental organizations in city Semnan). Quarterly Journal of Public Organzations Management, 8(2), 11-24. doi:10.30473/ipom.2020.49086.3832

Farrukh, M., Ying, C. W., \& Mansori, S. (2017). Organizational commitment: an empirical analysis of personality traits. Journal of Work-Applied Management.

Ghafuri, P., Farhadi, A., \& Mansouri, A. (2014). Relationship between intellectual capital and organizational agility with mediatory role of employee empowering in service sector (Case Study: Karafarin Insurance Company). International Journal of Economy, Management and Social Sciences, 3(12), 11-15.

Gopalakrishnan, M., Libby, T., Samuels, J. A., \& Swenson, D. (2015). The effect of cost goal specificity and new product development process on cost reduction performance. Accounting, Organizations and Society, 42, 1-11.

Haidari, M., Siadat, S. A., Hovaida, R., \& Shahin, A. (2014). The Relationship between Organizational Excellence Enablers and Organizational Agility Capabilities in Universities in Isfahan. Journal of New Approaches in Educational Administration, 5(17), 21-38.

Harraf, A., Wanasika, I., Tate, K., \& Talbott, K. (2015). Organizational agility. Journal of Applied Business Research (JABR), 31(2), 675-686.

Howson, C. (2007). Successful business intelligence: Tata McGraw-Hill Education.

Iqbal, A., Latif, F., Marimon, F., Sahibzada, U. F., \& Hussain, S. (2019). From knowledge management to organizational performance: Modelling the mediating role of innovation and intellectual capital in higher education. Journal of Enterprise Information Management, 32(1), 36-59.

Jourkesh, N., Shokrchizadeh, A. R., \& Sarjoui, S. (2015). Investigating the effect of organizational agility on the performance of employees: Isfahan Zamzam Company. Paper presented at the Second International Conference on Management and Economics in the 21st Century, Tehran.

Mahmoudi, A., Yousefi, B., Khazaei, A., \& Eskandari, S. (2019). Designing the related structural equation model of organizational intelligence and organizational performance in sport organizational experts of Tehran Municipality: The mediating function of the deployment process of Six Sigma. Journal of Sport Management, 11(1), 133-154. doi:10.22059/jsm.2017.235794.1868

Mosleh, A., \& Allahyari Bouzanjan, A. (2014). A Study of the Organizational Intelligence Effect on Technological Innovation in Knowledge-Based Enterprises. Management Studies in Development and Evolution, 23(73), 63-94.

Nafei, W. A. (2016). Organizational agility: The key to improve organizational performance. International Business Research, 9(3), 97-111.

Panda, S., \& Rath, S. K. (2018). Modelling the relationship between information technology infrastructure and organizational agility: A study in the context of India. Global Business Review, 19(2), 424-438.

Rezaei Kalantari, M., \& Nouri, A. (2020). The Relationship between Moral Intelligence and Organizational Intelligence with Job Performance of Mazandaran Province Police. NAJA HUMAN RESOURCES, 11(60), 85-108.

Rzepka, A., \& Bojar, E. (2020). Leadership as One of the Factors Shaping the Development of an Agile Organization. Review of Integrative Business and Economics Research, 9, 383-393. 
Saeed, R., Sami, A., Lodhi, R., \& Iqbal, A. (2013). Intellectual capital and organizational performance: An empirical study in telecom sector of Pakistan. Middle-East Journal of Scientific Research, 18(4), 517-523.

Sanadgol, M. (2014). The survey of relationship between organizational agility and principals job satisfaction. International Journal of Basic Sciences \& Applied Research, 3, 317-319.

Sharifi, H., \& Zhang, Z. (1999). A methodology for achieving agility in manufacturing organisations: An introduction. International journal of production economics, 62(1-2), 7-22.

Sherehiy, B., \& Karwowski, W. (2014). The relationship between work organization and workforce agility in small manufacturing enterprises. International Journal of Industrial Ergonomics, 44(3), 466-473.

Shiri, A., Mohsenimoghadam, A., \& Faizi, S. (2014). The relationshipbetweenorganizational intelligenceandorganizationalagility In Ilam state. Ilam Culture, 15(44-45), 22-36.

Steyrer, J., Schiffinger, M., \& Lang, R. (2008). Organizational commitment-A missing link between leadership behavior and organizational performance? Scandinavian Journal of management, 24(4), 364-374.

Urban, B., \& Joubert, G. C. D. S. (2017). Multidimensional and comparative study on intellectual capital and organisational performance. Journal of Business Economics and Management, 18(1), 84-99.

Yousef, D. A. (2017). Organizational commitment, job satisfaction and attitudes toward organizational change: A study in the local government. International Journal of Public Administration, 40(1), 7788 . 